\title{
Phenomenology and the Empirical Turn: a Phenomenological Analysis of Postphenomenology
}

\author{
Jochem Zwier ${ }^{1}$ - Vincent Blok ${ }^{2}$ • Pieter Lemmens ${ }^{1}$
}

Received: 5 October 2015 / Accepted: 4 May 2016 / Published online: 25 May 2016

(C) The Author(s) 2016. This article is published with open access at Springerlink.com

\begin{abstract}
This paper provides a phenomenological analysis of postphenomenological philosophy of technology. While acknowledging that the results of its analyses are to be recognized as original, insightful, and valuable, we will argue that in its execution of the empirical turn, postphenomenology forfeits a phenomenological dimension of questioning. By contrasting the postphenomenological method with Heidegger's understanding of phenomenology as developed in his early Freiburg lectures and in Being and Time, we will show how the postphenomenological method must be understood as mediation theory, which adheres to what Heidegger calls the theoretical attitude. This leaves undiscussed how mediation theory about ontic beings (i.e.,technologies) involves a specific ontological mode of relating to beings, whereas consideration of this mode is precisely the concern of phenomenology. This ontological dimension is important to consider, since we will argue that postphenomenology is unwittingly technically mediated in an ontological way. The upshot of this is that in its dismissal of Heidegger's questioning of technology as belonging to "classical philosophy of technology," postphenomenology implicitly adheres to what Heidegger calls technology as Enframing. We argue that postphenomenology overlooks its own adherence to the theoretical attitude and ultimately to Enframing, and we will conclude with calling for a phenomenological questioning of the dimension that postphenomenology presently leaves unthought, meaning that we will develop a plea for a rehabilitation of the ontological dimension in the philosophy of technology.
\end{abstract}

Keywords Postphenomenology · Empirical turn · Heidegger · Theoretical attitude · Enframing

Jochem Zwier

jzwier@science.ru.nl

1 Faculty of Science, Institute for Science, Innovation, and Society, Dept. of Philosophy and Science Studies, Radboud University Nijmegen, P.O. Box 9010, 6500 GL Nijmegen, The Netherlands

2 Philosophy Group, Wageningen University, P.O. Box 8130, 6700 EW Wageningen,

The Netherlands 


\section{Introduction}

Postphenomenology unmistakably belongs to the philosophies of technology that embrace what Hans Achterhuis (2001) has dubbed"the empirical turn." This implies a critical distance towards accounts in which technology appears as a singular overarching process and instead investigates technological dynamics on a micro-scale. Postphenomenology aims to empirically analyze how particular technologies as "the things themselves" mediate the relation between humans and their world. This has given rise to numerous analyses and detailed descriptions of how human existence is deeply and polymorphously interwoven with artifacts.

While acknowledging that the results of its analyses are to be recognized as original, insightful, and valuable, we will argue that in its execution of the empirical turn, postphenomenology forfeits a phenomenological dimension of questioning. This dimension can be brought to light by turning to the phenomenology of Martin Heidegger, whose work stands as both one of the most important sources of inspiration for postphenomenology as well as one of the most prominent targets of postphenomenological critique (cf. Ihde 2010, p. 1). By contrasting the postphenomenological method with Heidegger's understanding of phenomenology as developed in his early Freiburg lectures and in Being and Time, we will show how the postphenomenological method must be understood as mediation theory, which adheres to what Heidegger calls the theoretical attitude. This adherence leaves undiscussed how mediation theory about ontic beings (i.e., technologies) involves a specific ontological mode of relating to these beings, whereas consideration of this mode is precisely the concern of phenomenology (Section 3 and Section 4). This ontological dimension is important to consider, since we will argue that postphenomenology is unwittingly technically mediated in an ontological way. The upshot of this is that in its dismissal of Heidegger's questioning of technology as belonging to "classical philosophy of technology," postphenomenology unwittingly adheres to what Heidegger calls the essence of technology as Enframing. Our claim will be that postphenomenology overlooks its own adherence to the theoretical attitude and ultimately to Enframing, and we will conclude with calling for a questioning of the dimension that postphenomenology presently leaves unthought, meaning that we will develop a plea for a rehabilitation of the ontological dimension in the philosophy of technology (Section 6). In order to develop these points, we begin with a review of postphenomenology as a philosophical method for questioning technology (Section 2).

\section{The Postphenomenological Method}

In this section, we inquire into postphenomenology as a method for questioning technology and how this method derives from phenomenology. Since our aim consists in providing a clear formulation of the postphenomenological method, we will neither pursue historical comprehensiveness with regard to the discussion of classical phenomenology nor investigate the legitimacy of how the latter is appropriated by postphenomenology. Critical examination of the postphenomenological method is postponed to the next sections.

To understand postphenomenology as a method for studying technology, we can take Don Ihde's work as point of departure. Ihde provides the following equation: 
"pragmatism + phenomenology $=$ postphenomenology" (Ihde 2012, p. 117, p. 128). We first ask how phenomenology is part of the equation and subsequently investigate the meaning and implication of the addition of pragmatism.

\subsection{Phenomenology in Postphenomenology}

The postphenomenological questioning of technology ${ }^{1}$ departs from phenomenology, because the latter augments what Ihde calls a "naïve objectivist account" (1990, p. 97). Such an account would study technology in terms of perceived objective qualities such as physical or material properties. This is not deemed wrong, but too limited insofar as it solely regards technologies as quality-bearing objects from the perspective of a conscious subject that is positioned over against such an object. The insight taken from Husserl's phenomenology is that such a perspective is not a neutral starting point, but is itself the specifically structured product deriving from a prior experiential correlation. In its demand for a "radically empirical beginning" (Ihde 2012, p. 16), phenomenology observes the famous call by Husserl to move "to the things themselves," thereby following the phenomenological "principle of all principles":

that every originary presentive intuition is a legitimizing source of cognition, that everything originarily (so to speak, in its 'personal' actuality) offered to us in 'intuition' is to be accepted simply as what it is presented as being, but also only within the limits in which it is presented there. (Husserl 1983, p. 44)

Ihde adopts this maxim and accordingly defines phenomenology as "an examination of experience that deals with and is limited by whatever falls within the correlation of experienced-experiencing" (Ihde 2012, p. 34). This means not presupposing a structure in which subject and object are simply given as opposites, but beginning with and limiting oneself to the correlation of what is experienced (which Husserl called the noema or noematic correlate) with its mode of being experienced (the noesis or noetic correlate) (cf. Ihde 2012, p. 25). The correlation of noema and noesis is called intentionality, and careful description and examination of intentionality shows how a conscious subject cannot be simply presupposed as a starting point, but is discovered from within the movements of experience.

Postphenomenology finds one of its central ideas here. It claims that technologies cannot be reduced to quality-bearing objects that are perceived by a subject. Rather, technologies are woven into the movements of experience in ways that exceed the scope of objectivist accounts. Ihde's example of skilled woodchopping serves to illustrate this point. $^{2}$ When examined phenomenologically, i.e., when the analysis is limited to what is given in experience, the praxis of woodchopping shows how a conscious subject, an "I" or any noetic correlate for which technologies come into view as quality-bearing objects, is not plainly given from the start, but appears at a late stage in the analysis. For the skilled person engaged in woodchopping, "perceptual attention is concentrated upon the piece of wood to be cut" (Ihde 2012, pp. 29-30). The piece of wood stands out from the

\footnotetext{
${ }^{1}$ In this essay we focus on postphenomenology as developed by Don Ihde and Peter-Paul Verbeek.

${ }^{2}$ The fact that this example is quite obviously indebted to Heidegger rather than to Husserl is of historical, not of methodical importance for the present purposes.
} 
environment as the "focal core" (Ihde 2012, p. 30) to which conscious attention is directed, whereas one's axe, the various techniques associated with it (pose, aim, amount of applied force, etc.), as well as the notion of oneself as a cognizant subject are not primarily presented to perceptual experience. One becomes aware of oneself, one's environment, one's tools, and one's techniques only reflexively. So rather than simply perceiving a fully aware and conscious subject (e.g., the logger) that finds itself opposed to a defined object (e.g., the piece of wood), using a delineated tool-object (e.g., the axe with a certain weight, length, color, etc.), a phenomenological description of what Ihde calls the "straightforward experience" present in our practical engagement with the world yields an experiential correlation in which the noema, the piece of wood to be cut, is presented first (Ihde 2012, p. 27). What follows is that "[the] 'I', particularly in its thematized form, comes late in the analysis rather than being given as a first. This is to say, the 'I' has a certain genesis or recognizable origin in the movements of experience" (Ihde 2012, p. 29). Technologies (the axe in this example) do not solely appear as pregiven quality-bearing objects for conscious reflection by a pre-given "I" or subject, but are woven into the wider movements of experience. Postphenomenology calls this interweaving "technological mediation" and studies it under the heading of "humantechnology relations," with the goal of "[discovering] structural features of those ambiguous relations (Ihde 1990, p. 75; see also Ihde 1993, p. 71; Verbeek 2005, p.7). ${ }^{3}$

It may thus be clear how Husserlian phenomenology inspires postphenomenology to emphasize human-technology relations, thereby moving beyond a subject-object dichotomy (cf. Verbeek 2005, p. 110) to investigate technologically mediated relations in which "both the objectivity of the world and the subjectivity of those who are experiencing it and existing in it are constituted" (Verbeek 2011, p. 15; see also Verbeek 2005, pp. 111-113).

\subsection{Pragmatism in Postphenomenology}

In postphenomenology, the mediated constitution of subject and object involves pragmatism, the second term of Ihde's equation. Pragmatism is incorporated into postphenomenology to ward off the alleged essentialist thought present in classical phenomenology and philosophy of technology. ${ }^{4}$ Essentialism means the reference to an essence that transcends the experiential correlation, subject-object constitution, or human-technology relation. Ihde finds such essentialism in Husserl's phenomenology because Husserl ultimately grounds the phenomenological analysis in a transcendental subject, thereby falsely retaining the Cartesian "vestigial epistemology that still divides realities into something like bare material objects and something else like a meaning-

\footnotetext{
${ }^{3}$ Ihde has famously discovered several kinds of human-technology relations, called embodiment relations, hermeneutic relations, alterity relations, and background relations. Verbeek has suggested that what he calls cyborg relations and composite relations can be added to this scheme. Analysis of these types of relations is omitted here. For a more detailed discussion of these human-technology relations, see Ihde (1990, pp. 72112); Verbeek (2005, pp. 122-127; 2011, pp. 139-152).

${ }^{4}$ Postphenomenology follows the pragmatism as developed by John Dewey, and also makes occasional reference to William James and Richard Rorty. An elaborate study of the postphenomenological interpretation of these pragmatic philosophies is beyond the scope of this paper. Ihde (2009, pp. 5-25) provides a historically oriented review of postphenomenology and pragmatism. The question whether and how (some of) the arguments presented in these pages would have a bearing on pragmatism beyond the scope of postphenomenological pragmatism cannot be answered within the confines of this paper and is therefore left open.
} 
giving subject" (Ihde 2012, pp. 122-123). Likewise, with regard to technology, postphenomenology is critical of accounts in which technology is reduced to a singular, overarching essence. Culprits that are often mentioned in this regard are Karl Jaspers, Jacques Ellul, and most of all Martin Heidegger - to whom we will return. According to Ihde, postphenomenology is pragmatist insofar as it takes an "anti-essentialist" position: "I claim, pragmatically, that there is no essence of technology" (Ihde 2010, p. 119). Instead of viewing technologies according to a fixed essence, their character is considered to be "multistable" (2010, p. 126), meaning that a technology can assume various "stable" identities which depend on the context in which it is used. One of Ihde's examples concerns sardine cans that were left behind by gold prospectors in New Guinea, and were subsequently used as ornamental headgear by the local inhabitants (Ihde 1990, p. 125). Verbeek also adheres to this pragmatism: "[technologies] are only technologies in their concrete uses, and this means that one and the same artifact can have different identities in different use contexts" (2005, p. 118). ${ }^{5}$ For postphenomenology then, anti-essentialism means that the character of technologies is pragmatically defined, which is to say that it depends on use-context. Investigating specific technologies and their respective mediations as appearing in specific usecontexts implies investigating technologies empirically, or taking the empirical turn.

In light of this survey, we can define the postphenomenological method as the empirical inquiry into the structural ways in which particular technologies mediate experiential correlations and associated subject-object constitutions that appear in specific contexts of technology use.

\section{Postphenomenology and Pragmatism}

It may be observed that even though postphenomenology consists of phenomenology and pragmatism, it takes its name from the former rather than the latter. At least part of the rationale behind this can be found in Ihde's argument that postphenomenology, given its anti-essentialism, pragmatism, and empirical turn, is "more phenomenological" than its (essentialist) predecessors (Ihde 2010, p. 19; p. 128). This implies that pragmatism is in line with, and actually advances a phenomenological agenda. In this section, we begin to investigate this implication by questioning the phenomenological status of postphenomenological pragmatism. This will lay the groundwork for our critique of the fusion of phenomenology and pragmatism, which will be further developed in the next section. In order to do this, we first turn to the question what the phenomenon for postphenomenology is and ask how pragmatism is associated with this.

\subsection{The Phenomenon in Postphenomenology}

What is the phenomenon in postphenomenology? It is technology understood as a human-technology relation. For Verbeek: "Phenomenology ... is the philosophical analysis of the structure of the relations between human beings and their lifeworld" (2011, p. 7; our emphasis), and postphenomenology studies these relations in terms of

\footnotetext{
${ }^{5}$ For Verbeek, this also means that postphenomenology "overcomes ... the essentialism ... that characterized classical phenomenology" (2005, p. 113).
} 
human-technology relations. Ihde maintains that technology must be understood "phenomenologically, i.e. as belonging in different ways to our experience and use (...), as a human-technology relation, rather than abstractly conceiving of [technologies] as mere objects" (1993, p. 34; our emphasis).

This understanding of the phenomenon involves a noteworthy change in the understanding of the technological thing. When understood as phenomenon, a technology no longer appears as the self-contained thing that "naïve objectivism" yields, but as a humantechnology relation. When Ihde states that "... a technology is a human-technology relation" (1993, p. 40), he suggests that technology itself contains a variety of things. We have seen how the human-technology relation is understood as the site in which both objectivity and subjectivity are constituted (Section 2). This implies that objects and subjects are constituents, i.e., things that are constituted within the human-technology relation. To return to a previous example, Ihde's description of woodchopping demonstrated how the woodchopper (constituent 1) is constituted as woodchopper insofar as he embodies the axe (constituent 2) and is engaged in chopping a piece of wood (constituent 3 ), etc. In Verbeek's terms, “the 'subjectivity' of human beings and the 'objectivity' of their world are the result of mediations" (2012, p. 392). For postphenomenology, therefore, constitution is always the mediated constitution of things (constituents) within the confines of the phenomenon understood as human-technology relation. ${ }^{6}$

Accordingly, the postphenomenological questioning of technology concerns "what things do," as the title of Verbeek's book has it (2005). In light of the phenomenological interpretation of technology as human-technology relation and site of constitution, Verbeek's "things" do not solely refer to specific artifacts that mediate in experiential correlations (e.g., the thermometer mediating my interpretation of temperature), but to all constituents. Therefore, questioning "what things do" means investigating how the (mediated) constitution of things, subject and object alike, takes place in a humantechnology relation. In sum, the phenomenon of postphenomenology is the humantechnology relation, which further designates the site in which "things do," i.e., in which the (mediated) constitution of things as constituents takes place.

How does pragmatism relate to this understanding of the phenomenon? In what follows, we will develop the argument that it relates on two levels: first, the ontic level where it concerns the content of the phenomenon. This level is explicitly addressed in the postphenomenological method. The second level is ontological and concerns the access to the phenomenon. This level remains implicit in postphenomenology and will be made explicit by our analysis and introduction of a phenomenological concept of technical mediation. We will explain the former in the remainder of this section, and work our way towards the latter in Section 4.

\subsection{Content-Pragmatism}

On the first - ontic - level, pragmatism is included in postphenomenology to ensure correct descriptions of the phenomenon. Here, pragmatism concerns the content of the phenomenon, which is ontic insofar as it concerns the character of the beings or constituents within the human-technology relation. In what follows, we will refer to

\footnotetext{
${ }^{6}$ For an elaborate account of constitution in relation to technical mediation, see Kiran (2012a). For a critical analysis of "constitution" in postphenomenology, see Smith (2015).
} 
this as "content-pragmatism," It implies that postphenomenology denies the constituents in human-technology relations a stable, essential identity, and instead understands this identity in an anti-essentialist way, which is to say as multistable and dependent on use-context. Reiterating Ihde's example: within a specific human-technology relation, the subject is constituted as woodchopping-subject, the piece of wood is constituted as potential firewood, the axe is constituted as embodied, etc. ${ }^{7}$

The introduction of content-pragmatism is said to lead to a "more phenomenological" outcome (Ihde 2010, p. 19; p. 128). When we ask why this is more phenomenological, the answer is that it provides a more adequate depiction of the phenomenon or humantechnology relation. We can turn to the postphenomenological critique of Heidegger to see how this works. Our discussion will be limited to how the postphenomenological critique grounds in adequacy of analysis. ${ }^{8}$ Subsequently, we will investigate the appeal to adequacy itself, which paves the way for an evaluation of the critique.

Heidegger stands as a foundational example ${ }^{9}$ of classical and therefore inadequate philosophy of technology that is to be overcome by the introduction of pragmatism and the associated empirical turn. His famous "Question Concerning Technology" (1977) views the essence of modern technology as the way in which being reveals itself as Enframing. The latter means that the world appears as inventory of a standing reserve [Bestand] (Heidegger 2012, p. 34), as resource in the sense of a "gigantic gasoline station" [Riesentankstelle] (Heidegger 1969, p. 50), i.e., as a material and immaterial resource, always ready to be utilized and exploited at will. The forest now appears as potential firewood, the river appears as a power source for a hydroelectric dam or as a tourist attraction, etc. (cf. Blok 2014). Verbeek summarizes: "reality is understood in terms of what is available to and can be controlled by human beings" (Verbeek 2005, p. 52).

Ihde finds Heidegger's analysis to be essentialist, which means that all technologies are reduced to the same essence of Enframing. As Ihde rhetorically asks: "do all technologies fall under this description? No." (Ihde 2010, p. 120). Hence, the problem is that Heidegger fails to see that technologies are not "one size fits all" (Ihde 2010, p. 114), and Ihde provides many counterexamples that do not suit Heidegger's interpretation of technology as enframing, for instance, musical instruments (2010, pp. 122125). As Ihde concludes: "To attend to the 'essence' of technology, I argue, blinds Heidegger to the differing contexts and multidimensionalities of technologies that a pragmatic-phenomenological account can better bring forth" (2010, p. 115).

A similarly oriented critique is voiced by Verbeek, who sees Heidegger's analysis succumbing to the "Orphic temptation" (2005, p. 113) of solely looking backwards

\footnotetext{
${ }^{7}$ We should note that Ihde, building on the work of Rorty, further ties postphenomenological pragmatism to a "nonfoundational, nontranscendental, [and] anti-Cartesian" orientation (Ihde 2012, p. 116), and further follows Carl Mitcham's discussion of pragmatism as a "shift from a representationalist belief epistemology to an actional or practice-oriented analysis" (Ihde 2012, pp. 116-117). In this paper, we emphasize postphenomenological pragmatism in terms of anti-essentialism and multistability. The way we see it, antiessentialism marks the main postphenomenological response to foundationalism, transcendentalism, and Cartesianism. These are all grounded in an essence (e.g., the Cartesian ego, cf. Section 2.2), whereas postphenomenology contends that the character of things is not essential but is pragmatically constituted in contexts of action, practice, or use.

${ }^{8}$ For a more detailed discussion of the postphenomenological critique of Heidegger's question concerning technology, see Verbeek (2005, pp. 47-95); Ihde (2009; 2010).

${ }^{9}$ On multiple occasions, Ihde calls Heidegger the founder of philosophy of technology. See for example Ihde (1993, p. 103; 2010, pp. 28-55).
} 
towards conditions of possibility of technologies, where these conditions mean Enframing. ${ }^{10}$ In so doing, Heidegger "fails to connect with specific technologies" (2005, p. 95), as he neglects "what things do" in human-technology relations. Verbeek calls this "transcendentalism" and argues against it by claiming that analysis of technologies must also include "looking forwards" to see how actual involvement with technologies goes beyond enframing (cf. Verbeek 2005 pp. 144-145). As an example, an analysis of a car (driving, maintaining, etc.) cannot be reduced to the stockpiled beings that are the conditions for the car's being (construction materials, oil, electrical energy, air conditioner fluid, asphalt, etc.), but must be expanded in terms of how the car is embodied when driving it, how it mediates the constitution of one's identity, and so on. Because Heidegger overlooks these aspects by solely emphasizing the condition of possibility, the final verdict is that "Heidegger's transcendentalist approach is not able to give an adequate account of modern, technological artifacts" (2005, p. 94, our emphasis).

Both the critiques concerning essentialism and transcendentalism make clear that Heidegger's analysis is disregarded because it provides an inadequate description of technologies. Instead of reducing all of technology to the same essence or conditions of possibility, postphenomenology aims for a more appropriate depiction of technologies and therefore turns to empirical analysis of specific human-technology relations. Accordingly, essentialism and transcendentalism are countered with the empirical turn and are supplanted with multistability. This shows how content-pragmatism is grounded in adequacy of analysis.

\subsection{Adequacy and Phenomenology}

To summarize, we have seen how the phenomenon in postphenomenology is the human-technology relation, which is the site in which "things do," viz. in which mediated constitution takes place ("Phenomenology in Postphenomenology"). We have further seen that content-pragmatism provides a "more phenomenological," i.e., more adequate analysis of the phenomenon than provided by classical, "essentialist" or "transcendentalist" interpretations (Section 3.2). This gives rise to the following question: how must the appeal to adequacy be understood phenomenologically?

Adequacy is associated with truth as correspondence. In the traditional formulation: truth is the adequation of things and the intellect (veritas est adequatio rei et intellectus). Now, in its adoption of phenomenology, postphenomenology recognizes that such adequation belongs to a rather specific experiential correlation. Phenomenological analysis of intentionality does not assume a structure of correspondence between "things" and "intellect," because instead of presupposing the associated objective and subjective domains and asking how they correspond, phenomenology studies how such domains themselves have a genesis in the movements of experience (cf. Section 2). Again, following Ihde's analysis, the woodchopper is not primarily an "intellect" or subject that has adequate representations of "things" or objects, but rather he embodies the axe and focusses on the piece of wood to be cut. The question of the adequation of thing and intellect can only appear "later" upon reflection: it comes "late

\footnotetext{
${ }^{10} \mathrm{Cf}$. Ihde: "Heidegger [asks] a question that belongs to the transcendental tradition of philosophy: what are the set of conditions of possibility that make technology possible?" (2010, p. 31).
} 
in the analysis" (Ihde 2012, p. 29). Verbeek: "To understand oneself as a subject facing objects, an explicit act of separation is needed" (2011, p. 28).

This exposes an ambiguity with respect to the postphenomenological take on adequacy. On the one hand, postphenomenology regards the notion of adequacy to belong to a specific experiential correlation that cannot simply be presupposed, but must be analyzed as having a genesis in the movements of experience. On the other hand, postphenomenology adheres to adequacy in its appeal to content-pragmatism: multistability is presented as providing a more adequate account of technologies than essentialism or transcendentalism, which is to say that depicting technologies as multistable is more truthful than depicting them as Enframing.

The ensuing question is: if adequacy denotes a specific experiential correlation that cannot be presupposed when phenomenologically analyzing a woodchopper, would this not also be the case for a postphenomenological researcher analyzing humantechnology relations? Must the postphenomenological method not make a presupposition which makes it possible to adequately analyze human-technology relations as well as criticize other accounts (e.g., Heidegger's) for coming up short? Put differently: in what kind of experiential correlation is the postphenomenological researcher taken up when relying on content-pragmatism to provide an adequate depiction of the phenomenon? For an answer to these questions, we turn to Heidegger's phenomenology.

\section{Heidegger's Phenomenology}

In order to develop the question concerning the experiential correlation from which postphenomenology operates, we must begin by inquiring into Heidegger's understanding of phenomenology and the phenomenon. We therefore turn to the early Freiburg lectures as well as to Being and Time. The former are less frequently discussed than the latter in discourses about Heidegger, but there are two reasons to concentrate on the Freiburg lectures: first, Heidegger can here be found to lay the groundwork for his interpretation of phenomenology, which he will later take up in Being and Time. ${ }^{11}$ Second, and more importantly, we will see that the terms employed by Heidegger in the Freiburg lectures particularly resonate with what we hold to be the central problematic inherent in the postphenomenological method. They are therefore distinctly suited to elucidate the previously raised question pertaining to the postphenomenological appeal to adequacy and the experiential correlation from which this appeal is made. In what follows, we will make clear how Heidegger's understanding of phenomenology partly overlaps with the postphenomenological method, but argue that it also differs in two important ways: first, for Heidegger, the phenomenon of phenomenology is not the object of a theory. Second, phenomenology cannot be understood to be a theoretical science.

\footnotetext{
${ }^{11}$ This does not suggest that Heidegger's phenomenology from the Freiburg period is completely carried over to Being and Time without alteration. There are, for example, differences in the relation between the orientation of philosophy and science (cf. Blok 2005, pp. 56-72). We cannot elaborate on these differences in this paper, and instead focus on the continuum relating to the understanding of the phenomenon, which is central to our argument.
} 


\subsection{The Theoretical Attitude}

In Being and Time, Heidegger makes the frequently quoted claim that "Phenomenology signifies primarily a methodological conception. This expression does not characterize the what of the objects of philosophical research as subject-matter, but rather the how of that research" (Heidegger 2008, p. 50). This indicates an important difference between phenomenology and theoretical science. The latter is geared towards acquiring objective knowledge of the "what as subject-matter". Phenomenology holds that research about an object or domain of objectivity (a what) already involves a certain way of relating (a how) to this "what." 12 Scientific inquiry is not interested in this "how," but rather operates on the assumption that objects are accessible to theoretical thinking (e.g. via objective theory and scientific method). Conversely, this "how" is the theme of philosophy as phenomenology.

In further spelling out the difference between phenomenology and theoretical science, we can turn to Heidegger's Freiburg lectures, where he contrasts the phenomenological method with what he calls the theoretical attitude [Theoretische Einstellung] (Heidegger 2004, pp. 32-33). ${ }^{13}$ The theoretical attitude designates a specific mode of access to a theme of research, thereby involving a specific relation between being and thinking. Attitude here means that the theme of research stands as an object (being) over against the theoretical viewpoint of the researcher (thinking). The notion of the theoretical can be understood literally here $(\theta \varepsilon \omega \rho \varepsilon \tilde{v} v)$, as it denotes the taking of a perspective or view-point, ${ }^{14}$ which makes it possible to articulate propositions about the object and verify these for correctness. In aiming for correct theoretical propositions about objects, the sciences adhere to the theoretical attitude. This attitude is taken as self-evident and is not questioned (unlike the scientific content of propositions made by way of this attitude). For example, geneticists may study the structure and functions of (parts of) a genome, but do not ask how the genome appears as an object to experience and associated scientific theory.

According to Heidegger, the theoretical attitude is usually overlooked as a specific "how" because of an orientation towards objects and associated "knowledge of the objective order" [objektive Ordnungserkenntnis] (Heidegger 2001, p. 123). This orientation is marked by a care for the conformity of objects and theories, thereby following an "ordering, collecting, typifying tendency to classify" [ordnendsammelnden, typisierenden Klassifikationstendenz] (Heidegger 2001, p. 21; translation modified). The theoretical attitude is absorbed in this task of ordering and therefore overlooks how the terms that are to be aligned (i.e., objects and theories, viz. being and thinking) belong to a specific experiential correlation. Heidegger: "I direct myself only to the matter, I focus away from myself toward the matter. With this

\footnotetext{
${ }^{12}$ Recall our discussion of the postphenomenological method in $\$ 2.1$, where the subject-object relation is understood to involve a specific experiential correlation.

${ }^{13}$ For a full elaboration on Heidegger's criticism of the theoretical attitude and the development of his phenomenological method, see Blok (2005, pp. 64-84).

${ }^{14}$ It is worth noting that the translation of the corresponding passage from Being and Time is flawed. The German "jeweils" means "always," "each time," or "all the while" rather than "sometimes": "This kind of Being towards the world is one which lets us encounter entities within-the-world purely in the way they look ( $\varepsilon \tilde{i} \delta \mathrm{os})$... Looking at something in this way is sometimes (sic) a definite way of taking up a direction towards something - of setting our sights toward what is present-at-hand.” (Heidegger 2008, p. 88)
} 
'attitude' [Einstellung] the living relation to the object of knowledge has 'ceased' [eingestellt]..." (Heidegger 2004, p. 33). Here, having ceased means that this relation becomes an attitude in such a way that it is no longer considered as a relation. It becomes, to borrow an example from Aristotle, transparent like water for a fish.

To be sure, none of this is a critique in the sense of a value judgment. Heidegger refers to the theoretical attitude as the "sound instinct" of the sciences (2001, p. 121). ${ }^{15}$ However, he is critical of philosophical accounts that adhere to the theoretical attitude. ${ }^{16}$ If the principle of phenomenology is to investigate the things themselves as they show themselves, and if the theme of phenomenology is the relation between being and thinking, then phenomenology cannot prejudge this theme to be the object as observed from a theoretical perspective. This latter maneuver would not access the theme as it shows itself, but rather according to a specific mode of appearance that belongs to the specific experiential correlation associated with the theoretical attitude. For Heidegger, therefore, phenomenology cannot assume the theoretical attitude.

What follows is that the phenomenon of phenomenology is not simply the content of a theory, to wit, an object or objective domain in reality to be studied from a theoretical perspective. Rather, the phenomenon is not only the content [Gehalt], but also the relation [Bezug] between being and thinking that one always already has to enact [Vollzug] in order for such content to appear (cf. Heidegger 2004). In other words, the phenomenon of phenomenology is not itself an (ontic) object or a being, since all objectivity already presumes and enacts a relation (ontologically) between being and thinking, and this relation is precisely the theme of phenomenology. Along the same lines, phenomenology cannot be understood as a theoretical science regarding a specific domain of objects, since it simultaneously investigates the relation that has to be enacted in order to make objectivity possible.

This points to a fundamental difference between Heidegger's phenomenology and postphenomenology. Elucidating this difference will shed light on the previously raised question pertaining to the experiential correlation from which postphenomenology can appeal to adequacy (cf. Section 3.3). It subsequently facilitates a phenomenological analysis of postphenomenology.

\subsection{Postphenomenology as Mediation Theory}

We recall that the phenomenon in postphenomenology is the human-technology relation, the site in which "things do", viz. in which the mediated constitution of constituents (subjects, objects, artifacts etc.) takes place (Section 3.1). In light of Heidegger's understanding of the phenomenon and the theoretical attitude, we can see that the human-technology relation signifies a domain of reality, an objective "what" that is accessed theoretically. The postphenomenological method is geared

\footnotetext{
${ }^{15}$ This 'instinct' is not limited to the theoretical sciences. For Heidegger, it follows an orientation that rules throughout the tradition of western metaphysics. Cf. "A glance at the history of philosophy shows that formal determination of the objective [i.e., according to the theoretical attitude] entirely dominates philosophy" (Heidegger 2004, p. 43). A detailed discussion of this issue cannot be developed here. See for example Heidegger 2010, particularly $§ 10$. See also footnote 13 .

16 . Heidegger develops this point in a critique of Husserl's phenomenology. An inquiry into the details and justification of this critique is beyond the scope of this article. For a good discussion of this issue, see Bernet (1994).
} 
towards making adequate propositions about the human-technology relation. In order to do this, postphenomenology relies on content-pragmatism: if the human-technology relation is to be adequately depicted, essentialism and transcendentalism must be dismissed, and one must recognize how, within human-technology relations, the character of constituents is multistable and acquires stability depending on different use contexts. By way of its appeal to adequacy of analysis, we can observe that the postphenomenological understanding of the phenomenon is oriented towards what Heidegger called "knowledge of the objective order". Even though the content of this order is reinterpreted to be multistable and context-dependent, this order itself is accessed as an object, i.e. something that is literally thrown-opposite (obiectum) to the perspective of a postphenomenological researcher. This shows that postphenomenology adheres to the theoretical attitude. In alignment with the sciences, it ultimately aims to offer an adequate theory about phenomena called humantechnology relations and associated (mediated) constitution of pragmatically defined constituents. Verbeek is therefore right - more than he admits to - in referring to postphenomenology as "mediation theory" (2012; our emphasis). We previously asked in what kind of experiential correlation the postphenomenological researcher is taken up when relying on content-pragmatism to provide an adequate depiction of phenomena. The answer we now arrive at is: the experiential correlation characterized by the theoretical attitude.

This diagnosis does not involve a devaluation of postphenomenology's theoretical merits. It is evident that mediation theory opens up a rich dimension with regard to the questioning of technologies that remains foreclosed to any "naive objectivism". Further, recalling Section 3, we can say that Ihde is justified in suggesting that postphenomenology advances a phenomenological agenda and can even be said to be "more phenomenological" insofar as it discloses the intricacies of technologically mediated constitution that takes place in human-technology relations. Our diagnosis also suggests, however, that a phenomenological way of questioning has more to offer than postphenomenology presently acknowledges. Whereas mediation theory is principally about the content of the phenomenon, Heidegger's work indicates that phenomenology is not solely about the (ontic) content or "the what", but simultaneously about the (ontological) relation between being and thinking or "the how" that is already enacted in an encounter with such content. This gives rise to the idea that notwithstanding its theoretical virtues, the postphenomenological method neglects "the living relation to the object of knowledge", which is to say that it overlooks the element in which it is itself absorbed when confronting human-technology relations.

\section{Postphenomenology, Technical Mediation, Enframing}

All of this calls for elaborating an analysis of postphenomenology that advances on a phenomenological path left unexplored by mediation theory. In what follows, we take postphenomenology itself as phenomenon and further analyze its adherence to the theoretical attitude. This introduces pragmatism on a different, ontological level, which we specify by means of a reinterpreted, genuinely phenomenological concept of technical mediation. This in turn gives rise to a renewed confrontation with Heidegger's understanding of the essence of technology as Enframing. 


\subsection{Postphenomenology and the Phenomenon of Technical Mediation}

We have argued that the postphenomenological method adheres to the theoretical attitude (Section 4.2). The ensuing question is where postphenomenology as mediation theory finds it ground. The problem encountered at this juncture is that several traditional answers are prohibited. If the theoretical attitude marks a relation between being and thinking, then it is noteworthy that neither the side of being nor that of thinking can provide a ground for propositions about human-technology relations. This can be clarified by asking a simple question: why are the postphenomenological propositions about human-technology relations more adequate than those of Heidegger? Is it because postphenomenological theory represents what the world is really like and Heidegger has failed to notice this? Such an answer would eventually rely on invoking an essence on the part of being or objectivity. This is prohibited by the anti-essentialist character of postphenomenology. Is it more truthful because of how our thinking of the world is necessarily structured? This would invoke both transcendentalism and essentialism on the part of thinking or subjectivity, which cannot be allowed for similar reasons. We thus encounter a peculiar situation. By incorporating contentpragmatism and having multistability trump essentialism, postphenomenology claims to offer a more adequate theory about phenomena called human-technology relations. Yet it remains unclear on what grounds this theory can be said to be adequate.

Verbeek recognizes the abovementioned difficulty and argues that it would be inconsistent to make appeals to either transcendentalism or realism, because this would solicit an essence which postphenomenology cannot allow (2005, p. 113). He goes on to make the important observation that the fact that things "are accessible only in mediated ways does not interfere with our ability to say something about the roles they play" (2005, p. 113). Although Verbeek is right-and the growing collection of postphenomenological studies attests to this fact - it does seem to interfere with one's ability to invoke adequacy and claim that what one says about human-technology relations is more adequate than what Heidegger says about them.

This ambiguity gives rise to the question what "mediated access" means. For Verbeek, it means that the things studied by postphenomenology are always constituted in human-technology relations and cannot be traced back to some primordial quality or essence outside of those relations (cf. Section 3.1). ${ }^{17}$ However, we must now add to this that the human-technology relation is itself accessed in a "mediated way," since access is mediated by the theoretical attitude. If we further scrutinize this theoretical mediation in light of the abovementioned ambiguity pertaining to theoretical adequacy, the theoretical mediation appears as technical mediation. This can be made clear by returning to the postphenomenological critique of Heidegger.

In retrospect of the development of his own thought, Ihde reiterates what we can now call his theoretically mediated critique of Heidegger's essentialism and its inadequate "one size fits all" approach: "I saw that for Heidegger, every technology ended up with exactly the same output or analysis" (Ihde 2006, p. 271, original emphasis; cf. Section 3.2). He then goes on to say about Heidegger's analysis of technology:

\footnotetext{
${ }^{17} \mathrm{cf}$. "Only in this sense is postphenomenology a relativistic philosophy - it finds its foundation in relations" (Verbeek 2005, p. 113).
} 
As a pragmatist and a rigorous phenomenologist, I realized this meant, simply, that such an analysis was useless, since it could not discriminate between the results of playing a musical instrument, also a technological mediation, and the process of genetic manipulation! (Ihde 2006, p. 271, original emphasis)

This is repeated more strongly when Ihde discusses other critiques leveled at Heidegger, and finally claims: "I think the more biting criticism ... is that it has no utility" (Ihde 2006, p. 272, original emphasis).

Without doubt, Ihde's remarks concerning the difference between genetic manipulations and musical instruments are intended to be hyperbolic ${ }^{18}$, but more important than these somewhat overblown examples is the shift in the critique's orientation. The appeal to adequacy of analysis is now reoriented towards utility: the final problem with Heidegger is not that his analysis is inadequate in the sense of getting "too much wrong" (Ihde 2006, p. 271), but that it lacks utility. Utility here means that propositions about technologies have a further practical or theoretical use. For instance, in Ihde's work in particular, further theoretical uses have been developed in terms of the historical study of science and technology, where he discusses the technological embedding of various scientific discoveries (Ihde 2001). Now, the yields of these studies are not disputed here, but the reorientation towards utility invites phenomenological questioning. On the one hand, Ihde's postphenomenology is theoretically mediated insofar as it aims for adequate propositions about human-technology relations. On the other hand, this theoretical mediation is itself pragmatic insofar as it grounded in utility and effect, and can therefore be understood as technical mediation. This latter concept of technical mediation differs from the postphenomenological concept of technological mediation. It does not primarily concern the ontic content of human-technology relations in terms of content-pragmatism, viz. the technologically mediated constitution of things within those relations (e.g. the axe mediating the constitution of the woodchopper; cf. Section 3.1). Rather, the concept of technical mediation is phenomenological and ontological in a sense that is not thematized in postphenomenology and that characterizes the pragmatic horizon towards which the understanding of the phenomenon is oriented. ${ }^{19}$

Verbeek's solution to the aforementioned difficulty pertaining to the grounding of mediation theory indicates a similar orientation. While consistently following the idea that things are accessible only in mediated ways, he argues:

The ambition of the postphenomenological perspective is in no way to formulate a theory that aims to 'explain' empirical reality. My ambition is not to seek out laws that reality obeys, but rather to find concepts with which to make visible and understand as many aspects of reality as possible. (Verbeek 2005, p. 162)

\footnotetext{
${ }^{18}$ Ihde also offers more nuanced evaluations of Heidegger, for example with respect to gigantic industrial technologies, where he finds Heidegger's analysis to be "insightful and penetrating" (2010, p. 119). See also footnote 9 .

${ }^{19}$ Our phenomenolotical concept of technical mediation does not imply that postphenomenology can be reduced to a simple utilitarianism. To point is not that postphenomenology only pursues utility, but rather that utility and effect are presupposed in adequately theorizing about phenomena called human-technology relations.
} 
The interpretation of "aspects" matters a great deal at this juncture. If these aspects are considered on the ontic level of human-technology relations studied by mediation theory, then the touchstone for this theory ultimately comes down to "what it does", viz. what it makes visible. In fact, Verbeek proceeds in this way. Recalling the critique of Heidegger, it becomes clear that Heidegger's analysis is deemed inadequate insofar as it does not sufficiently disclose the intricacies of human-technology relations:

The most important critique (...) is that Heidegger does not fully succeed in developing an adequate (...) perspective on technology, for he reduces technology to its conditions of possibility and thereby fails to connect with specific technologies. (Verbeek 2005, p. 95)

Building on this critique, postphenomenology explores more effective paths, for example in ethical and political deliberation, where it contributes to robust imagination of the consequences of specific technologies and their respective mediations. As Verbeek says: "Technologies are political, and the theory of mediation can help to anticipate, analyze, and modify this 'material politics"' (Verbeek 2009, p. 260). Along the same lines, postphenomenological studies have been geared towards technologydesign, where they effectively help designers to consider how their designs mediate experience and the constitution of subjectivity: "Technology design, then, becomes a "continuation of politics by other means"' (Verbeek 2009, p. 257). ${ }^{20}$ As in the case of Ihde's historical work, the value of these efforts is not disputed here. Further, the critique of Heidegger can be accepted to the extent that it concerns the theoretical analysis of human-technology relations. Importantly however, a phenomenological questioning makes clear that these human-technology relations are accessed in a theoretically mediated way, and that the theory about these relations is technically mediated insofar as its adequacy of analysis consists in "what it does". Verbeek is therefore right in stating that "things are only accessible in mediated ways", but we can now see that this mediation - which must be phenomenologically interpreted as technical mediationconcerns the postphenomenological method in a way that it does not itself recognize.

\subsection{Technical Mediation and Enframing}

We have argued that postphenomenology is itself technically mediated in an ontological way. In this sense, technical mediation has a threefold meaning: first, it means that the phenomena called human-technology relations are presented as objects for mediation theory (theoretical mediation). Second, the character of this object and its contents is pragmatically defined (content-pragmatism). Third, the theory about this object is itself technical inasmuch as it is oriented towards a pragmatic horizon of utility and effect. Whereas postphenomenology explicitly takes account of technological mediation on the ontic level of human-technology relations, it overlooks its own technical mediation at an ontological level.

Still, Verbeek's account can also be interpreted to leave room for a phenomenological questioning of technical mediation. His previously cited remarks about the ambition of the postphenomenological perspective suggest that its method remains an

\footnotetext{
${ }^{20}$ For the connection of postphenomenology and design, cf. Dorrestijn (2012); Kiran (2012b); Verbeek (2005, pp. 203-236; 2011).
} 
unfinished project. Now, if this ambition consists in finding "concepts with which to make visible and understand as many aspects of reality as possible" (Verbeek 2005, p. 162), our phenomenological concept of technical mediation can be understood to contribute to this project. It shows how the mentioned "aspects of reality" cannot be limited to (ontic) human-technology relations accessed by mediation theory, but must further involve the (ontological) relation between being and thinking that is involved in encountering these relations. In light of this, we argue that Heidegger's notion of Enframing has been prematurely dismissed by postphenomenology and must be rehabilitated as highly relevant for an ontological questioning of technology.

The central point is that Heidegger's understanding of the essence of modern technology - Enframing - concerns what we have discussed in terms of the phenomenological concept of technical mediation, and can therefore neither be reduced to essentialism (Ihde) nor transcendentalism (Verbeek). Both these critiques are situated on the ontic level of humantechnology relations and accordingly interpret Enframing as a flawed proposition about these relations. Ihde interprets Enframing as a genus and criticizes it because one cannot reduce the complexities of human-technology relations to an overarching essence. ${ }^{21}$ Verbeek interprets Enframing as a condition of possibility for modern technologies and finds that human-technology relations cannot be reduced to these conditions (cf. Section 3.2). Yet Heidegger argues that "Enframing is never the essence of technology in the sense of a genus" (1977, p. 29), which indicates that it is not geared towards a theoretical description of technologies or human-technology relations. Rather, if we allow for a slight anachronism and use terms from the "early" Freiburg period (cf. Section 4) to discuss the "later" questioning of technology, we can say that Enframing does not primarily concern the content [Gehalt] of phenomena called human-technology relations, but concerns a relation $[$ Bezug] that we already enact [Vollzug] in encountering these phenomena. ${ }^{22}$ Understood on this ontological level, Enframing means a reciprocal setting-upon $[\text { stellen }]^{23}$ of being and thinking with regard to function (cf. Blok 2014), which is technical inasmuch as utility marks the main trait of the horizon toward which all experiential correlations are oriented. ${ }^{24}$ As in the case of the theoretical attitude, this orientation is

\footnotetext{
${ }^{21}$ Recall Ihde's previously encountered question: "do all technologies fall under this description? No." (2010, p. 120, our emphasis).

22 This indicates a continuity between Heidegger's early phenomenology and later work. Of course, this should not be taken to imply that the "early" and "late" Heidegger simply fit into a seamless whole. As is well known, the orientation of Heidegger's philosophy changes, particularly with respect to the famous "Turning." The details of this are well documented and are not repeated here (cf. Pöggeler 1987). The important point for our paper is that the thought about the difference between ontic and ontological constitutes a continuity in Heidegger's work. The (rather complex) details of this are of lesser importance for our argument, since we argue that postphenomenology overlooks the ontological question with respect to both Heidegger's early phenomenology, as well as his later work on the essence of technology.

${ }^{23}$ Heidegger's use of the german verb "stellen" has proven rather difficult to translate. To indicate the affinity of the later Question Concerning Technology with the early Freiburg lectures discussed in Section 3, it is worth pointing out that the theoretical attitude is originally called "Theoretische Einstellung", setting-upon is "stellen", represent is "vorstellen" and Enframing is Ge-stell. A further study of Heidegger's use of stellen is beyond the scope of this article. For more elaborate remarks on the translation of stellen, cf. Heidegger (1977, p. 15, footnote 14; 2012 pp. 25-27).

24 This is not to say that "utility" sufficiently covers what Heidegger means with "challenging forth" [herausfordern] that marks the way of revealing that belongs to modern technology (Heidegger 1977, p. 14). This further involves calculability, assurance of availability, and will to power. It is clear, however, that utility marks a necessary, even chief characteristic of the mode of revealing associated with technology as Enframing.
} 
assumed as self-evident. As Heidegger says: "Humans, in their relation to what presences are already challenged [herausgefordert] in advance, and therefore everywhere, and thus constantly, to represent what presences as something orderable for a requisitioning [das Bestellbare des Bestellens]" (Heidegger 2012, p. 29). Now, due its own technical mediation, the postphenomenological method unwittingly exemplifies this being "challenged in advance". On the one hand, it aims to "represent what presences" in an adequate mediation theory (Section 4). On the other hand, this theory is legitimated in terms of utility, i.e., "as something orderable for a requisitioning" (Section 5.1). Hence, postphenomenology dismisses Heidegger's questioning of technology because it provides an insufficiently useful theory, and in so doing unwittingly affirms Enframing.

Importantly, adherence to Enframing cannot be understood as a vilification. It is not wrong to develop a fruitful theory about technologies, mediations, multistabilities, etc. For Heidegger, Enframing does not denote some human failure and can therefore not be mobilized as a term of abuse. Although he regularly disparages modern technology, his questioning cannot be reduced to a value judgment. The point is not to condemn modern technology as demonic (1977, p. 28) but to take it into consideration as a "way of revealing" (1977, p. 12) Hence, if phenomenology asks how things are revealed, and if the postphenomenological method unwittingly adheres to the way of revealing associated with technology in the sense of Enframing, then a phenomenological study of technology must recognize this as a philosophical concern and task.

\section{Rehabilitating the Ontological Dimension: a Research Agenda}

In light of the above, we plead for a rehabilitation of the ontological dimension in the questioning of technology. Heidegger's question concerning the essence of modern technology has not simply been surpassed, and cannot be dismissed as "classical" in the sense of "outdated" philosophy of technology, since it takes consideration of an ontological structuring of reality to which the postphenomenological method unequivocally adheres. Such an orientation is not exclusive to postphenomenology, but appears as a chief characteristic of the present epoch. Rehabilitating the ontological dimension first of all points to the philosophical task of taking consideration of this phenomenon. Evidently, this task remains to be taken up and cannot be accomplished here. Yet, in following up on the arguments and analyses presented in this paper, we will conclude by sketching a number of trajectories pertaining to this task.

First, a rehabilitation of the ontological dimension puts the topic of metaphysics and essentialism back on the agenda. We have shown that the postphenomenological method is not as "anti-essentialst" (Ihde 2009, p. 10) as it considers itself to be. Although Ihde may be right in stating that there "is no essence of technology" (2010, p. 119) on the level of human-technology relations, the postphenomenological method encounters these relations in a technically mediated way, thereby involving the essence of technology in Heidegger's sense of Enframing. Rehabilitating an ontological consideration of this essence gives rise to the question whether Enframing implicates the whole of being and every access we have to beings. Our paper then serves as a corrective to understanding 
and criticizing the totalizing aspect of Enframing according to an interpretation of essence as genus (Section 5.2) and opens a different line of critical inquiry: with regard to technology, Heidegger understood all making, designing, and willing of technologies to be anchored in the mode of revealing that belongs to technology as Enframing. He therefore himself turned towards an exploration of the possibility of a non-technical, non-willing, "gelassen" way of philosophical thinking (Heidegger 1969; cf. Blok 2011a, p. 195). One can question, however, whether each technical making and willing can be reduced in such a radical way, and explore the possibility of a concept of making and willing that cannot be limited to technology in Heidegger's sense (cf. Blok 2013). This could be a locus for a renewed encounter between the ontological dimension articulated by Heidegger and philosophy of technology after the empirical turn. Among others, it opens the question about the relation between the "work" of technology in the sense of Enframing and the notion of "work" that Heidegger discusses in "The Origin of the Work of Art" (Heidegger 2002, pp. 1-56). In the former, work is considered in terms of utility and function which adhere to the way of revealing of Enframing. In the latter, the creation of the work of art is considered in terms of establishing truth, which is to say as an ontological moment beyond mere adherence. ${ }^{25}$ The question that would follow is which understanding of "making" holds sway in Heidegger's thought, how this contrasts with insights deriving from philosophy of technology after the empirical turn, and how this relates to abovementioned discussions regarding the totality of technology.

Secondly, attention to the ontological dimension raises the question pertaining to the meaning and implications of the empirical in an empirical philosophy of technology. As it stands, the empirical turn focuses on concrete technical artifacts. In light of this paper, we can ask whether focusing on concrete technological things is sufficiently empirical. To be empirical in the phenomenological sense would mean to take heed of what is most nearby, which is to say of the relation between being and thinking that is usually overlooked and taken as self-evident. This gives rise to a question that takes inspiration from both postphenomenology as well as Heidegger, and involves a renewed encounter between the two. On the one hand, our paper shows that postphenomenology is susceptible to the critique that it is not sufficiently empirical, since it overlooks how its own method is technically mediated. On the other hand, we can adopt (but must also adapt) a postphenomenological line of inquiry and ask whether Heidegger takes sufficient consideration of concrete artifacts. Again, this would not be to demonstrate how concrete artifacts are not "one size fits all" and cannot be subsumed under the genus called Enframing. Rather, the question would concern the relation between the ontic (artifacts) and the ontological (the way of revealing). It asks whether and how technological artifacts can be said to "mediate" on an ontological level. Do artifacts merely respond to a way of being, or can they also be considered to "mediate" how being reveals itself (cf. Lemmens 2015)? As a speculative example: What is the relation between the artefact called camera obscura and reality understood as res extensa? Postphenomenology does not address such a question because its empirical scope is limited to ontic human-technology relations. Heidegger does not address this question because for him, concrete artifacts are only encountered by way of the revealing of

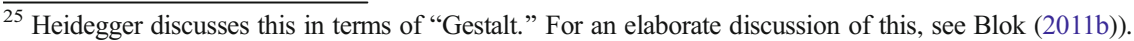


modern technology. ${ }^{26}$ The rehabilitation for the ontological dimension called for in this paper then points to a reconsideration of the relation between empirical artifacts and the meaning of the empirical in the phenomenological sense.

Finally, and more concretely, we point to the topic of ecology. Postphenomenology has regularly been criticized for exceedingly narrowing the scope to concrete artifacts and their uses, thereby neglecting the background conditions of these artefacts, be in terms of politics (cf. Feenberg 2009; Kaplan 2009; Smith 2015) or with regard to ethics and the good life (cf. Scharff 2012). The rehabilitation of the ontological dimension called for in this paper can be taken to move in a similar direction, but can be specifically oriented towards ecology. This topic is of interest because in a basic yet fundamental way, our present ecological situation can be understood as a fundamental "how" of how things appear to us. Put bluntly, it raises the question whether the "gigantic gasoline station" that Heidegger mentions in his discussion of Technology now appears to be encounter a limit insofar as it is leaking, which is to say that it is polluting the planet (cf. Zwier et al. 2015). It is clear that this situation is deeply related to the topic of technology, be it in terms of causes, diagnosis, or (potential) remedies. The question that follows from a rehabilitation of the ontological dimension in phenomenology of technology asks whether the relation between ecology and technology solely concerns the ontic (e.g., polluting vs "green" artefacts) or whether it must also be contemplated in ontological terms. A possible line of inquiry involves the relation between world and earth. Postphenomenological analyses of technologies generally concern how technologies understood as human-technology relations help constitute a world (cf. Section 2.1). Yet our present ecological situation indicates something that resists incorporation in our meaningful worlds. Understood in terms of planetary ecological dynamics, the earth now appears carrying these mentions worlds, while also tending towards the large-scale disintegration of these worlds. ${ }^{27}$ The task for phenomenology of technology would be to interpret this situation as phenomenon, which is to say as concerning the "what" (e.g., human-technology relations constitutive of worlds), while further involving how these worlds appear to us, and whether this "how" involves a mutation in due to the earth appearing as unworldly.

These trajectories are mere sketches to indicate directions for future research associated with a rehabilitation of the ontological dimension that we argued for in this paper. They become feasible only if postphenomenology is recognized to be technically mediated in the phenomenological sense portrayed here, and if this mediation is considered as a concern for philosophy of technology.

\footnotetext{
${ }^{26}$ Still, one can detect a tension in Heidegger's thought concerning this issue, which serves to legitimize our question. In Discourse on Thinking, for instance, Heidegger suggests that with the advent of synthetic biology (ontic), an attack upon the "nature of man" (ontological) is being prepared "with technological means" (Heidegger 1969, p. 52).

${ }^{27}$ Timothy Morton (2013) therefore announces "The end of the World", implying that the phenomenological notion of world is no longer meaningful in light of our ecological situation, which he mainly understands in terms of global warming. For a good discussion of the "asymmetry" of the earth as dynamic, see Clark (2011).
} 
Acknowledgments We wish to thank the anonymous referees for their valuable suggestions.

Open Access This article is distributed under the terms of the Creative Commons Attribution 4.0 International License (http://creativecommons.org/licenses/by/4.0/), which permits unrestricted use, distribution, and reproduction in any medium, provided you give appropriate credit to the original author(s) and the source, provide a link to the Creative Commons license, and indicate if changes were made.

\section{References}

Achterhuis, H. (Ed.). (2001). American philosophy of technology: The empirical turn (trans: Crease, R.P.). Bloomington: Indiana University Press.

Bernet, R. (1994). Phenomenological reduction and the double life of the subject. (trans: Renaud, F.). In T. Kisiel \& J. van Buren (Eds.), Reading Heidegger from the start: Essays in his Earliest Thought (pp. 245268). Albany: SUNY Press.

Blok, V. (2005). Rondom de vloedlijn. Filosofie en kunst in het machinale tijdperk. Een confrontatie tussen Heidegger en Jünger. Soesterberg: Uitgeverij Aspekt.

Blok, V. (2011a). An indication of being - reflections on Heidegger's engagement with Ernst Jünger. Journal of the British Society for Phenomenology, 42(2), 194-208.

Blok, V. (2011b). Establishing the truth: Heidegger's reflections on Gestalt. Heidegger Studies, 27, 101-118.

Blok, V. (2013). Towards the rehabilitation of the will in contemporary philosophy. Journal of the British Society for Phenomenology, 44(3), 285-301.

Blok, V. (2014). Reconnecting with nature in the age of technology: the Heidegger and radical environmentalism debate revisited. Environmental philosophy, 11(2), 307-332.

Clark, N. (2011). Inhuman nature: Sociable life on a dynamic planet. London: Sage Publications.

Dorrestijn, S. J. (2012). The design of our lives: Technical mediation and subjectivation after Foucault. Enschede: University of Twente Press.

Feenberg, A. (2009). Peter-Paul Verbeek: review of what things do. Human Studies, 32(2), 225-228.

Heidegger, M. (1969). Discourse on thinking. (trans: Anderson, J. M. \& Freund, H.). New York: Harper \& Row.

Heidegger, M. (1977). The question concerning technology and other essays. (trans: Lovitt, W.). New York: Harper and Row.

Heidegger, M. (2001). Phenomenological interpretations of Aristotle. (trans: Rojcewicz, R.). Bloomington: Indiana University Press.

Heidegger, M. (2002). Off the beaten track. (trans: Young, J. \& Haynes, K.). Cambridge: Cambridge University Press.

Heidegger, M. (2004). The phenomenology of religious life. (trans: Fritsch, M. \& Gosetti-Ferencei, J. A.). Bloomington: Indiana University Press.

Heidegger, M. (2008). Being and Time. (trans: Macquarrie, J. \& Robinson. E.). New York: Harper \& Row.

Heidegger, M. (2010). Logic. The question of truth. (trans. Sheehan. T.). Bloomington: Indiana University Press.

Heidegger, M. (2012). Bremen and Freiburg lectures. Insight into that which is and basic principles of thinking. (trans: Mitchell, A. J.). Bloomington: Indiana University Press.

Husserl, E. (1983). Ideas pertaining to a pure phenomenology and to a phenomenological philosophy. First book: General introduction to a pure phenomenology. (trans: Kersten, F.). The Hague, Boston, Lancaster: Martinus Nijhoff Publishers.

Ihde, D. (1990). Technology and the lifeworld: from garden to earth. Bloomington: Indiana University Press.

Ihde, D. (1993). Postphenomenology: essays in the postmodern context. Evanston: Northwestern University Press.

Ihde, D. (2001). Instrumental realism: the interface between philosophy of science and philosophy of technology. Bloomington: Indiana University Press.

Ihde, D. (2006). Forty years in the wilderness. In E. Selinger (Ed.), Postphenomenology: a critical companion to Ihde (pp. 267-290). New York: SUNY Press.

Ihde, D. (2009). Postphenomenology and technoscience: The Peking University lectures. Albany: SUNY Press. Ihde, D. (2010). Heidegger's technologies: postphenomenological perspectives. New York: Fordham University Press.

Ihde, D. (2012). Experimental phenomenology: Multistabilities (2nd ed.). Albany: SUNY Press.

Kaplan, D. M. (2009). What things still don’t do. Human Studies, 32(2), 229-240. 
Kiran, A. H. (2012a). Technological presence: actuality and potentiality in subject constitution. Human Studies, 35, 77-93.

Kiran, A. H. (2012b). Responsible design. A conceptual look at interdependent design-use dynamics. Philosophy \& Technology, 25, 179-198.

Lemmens, P. (2015). Van Ontologie naar organologie. Heidegger en Stiegler over het gevaar en de ambivalentie van de techniek. De Uil van Minerva, 28(4), 335-362.

Morton, T. (2013). Hyperobjects: Philosophy and ecology after the end of the world. Minneapolis: University of Minnesota Press.

Pöggeler, O. (1987). Martin Heidegger's Path of Thinking. (trans: Magurshak, D \& Barber, S). Atlantic Highlands, N. J.: Humanities Press International.

Scharff, R. C. (2012). Empirical technoscience studies in a Comtean world: too much concreteness? Philosophy \& Technology, 25, 153-177.

Smith, D. (2015). Rewriting the Constitution: A Critique of 'Postphenomenology'. Philosophy \& Technology, 28(4), 553-551.

Verbeek, P. P. (2005). What Things do: philosophical reflections on technology, agency, and design (trans: Crease, R.P.). Pennsylvania: Penn State University Press.

Verbeek, P. P. (2009). Let's make things better: a reply to my readers. Human Studies, 32, 251-261.

Verbeek, P. P. (2011). Moralizing technology: understanding and designing the morality of things. Chicago and London: University of Chicago Press.

Verbeek, P. P. (2012). Expanding mediation theory. Foundations of Science, 17(4), 391-395.

Zwier, J., Blok, V., Lemmens, P., Geerts, R. J. (2015). The ideal of a zero-waste humanity: philosphical reflections on the demand for a bio-based economy. Journal of Agricultural and Environmental Ethics, 28(2), 353-374. 